\title{
Evaluation of Hepatoprotective Effect of a Polyherbal Megakutki against Paracetamol-Induced Hepatotoxicity
}

\author{
Asha Elizabeth Giri', Vanishree Rao', Sandeep Singhal', Karthik Gourishetti ${ }^{1}$, Subhankar Biswas ${ }^{1}$, \\ Krishnadas Nandakumar', Mallikarjuna Rao Chamllamudi ${ }^{1}$, Jeetesh Dave ${ }^{2}$, Rakesh Dave ${ }^{2}$, Suhani \\ Sumalatha ${ }^{3}$, Nitesh Kumar ${ }^{1,4, *}$
}

'Department of Pharmacology, Manipal College of Pharmaceutical Sciences, Manipal Academy of Higher Education, Manipal, Karnataka, INDIA

${ }^{2}$ Umalaxmi Organics Pvt. Ltd., Agro Food Park Industrial Area, Boranada, Jodhpur, Rajasthan, INDIA.

${ }^{3}$ Department of Anatomy, Kasturba Medical College, Manipal Academy of Higher Education, Manipal, Karnataka, INDIA.

${ }^{4}$ Department of Pharmacology and Toxicology, National Institute of Pharmaceutical Education and Research, Hajipur, Export

Promotions Industrial Park (EPIP), Industrial Area Hajipur, Vaishali, BIHAR, INDIA.

\begin{abstract}
Background: Megakutki ${ }^{\circledast}$ (MK) is a polyherbal preparation of 11 standardized extracts that are individually proven for hepatoprotection scientifically. Aim: Study evaluated MK's hepatoprotective potential against paracetamol (PCM) in in-vitro on Hep G2 cells using cell viability, cell cycle analysis and apoptotic studies and in in-vivo in Wistar rats using liver function tests, histological and DNA fragmentation study. Materials and Methods: In in-vitro studies, $\mathrm{IC}_{50}(50 \%$ inhibition in viability) values of silymarin, $\mathrm{MK}$ and PCM were found out by MTT assay. In-vitro hepatoprotection was found out by pretreating the cells with below- $\mathrm{IC}_{50}$ concentrations of $\mathrm{MK}$ and silymarin for $24 \mathrm{~h}$ followed by PCM (at IC $\mathrm{C}_{50}$ concentration) challenge for next $24 \mathrm{~h}$ and $\%$ viability was evaluated using MTT assay. Same treatment protocol was followed for cell cycle analysis and apoptotic studies $(100$ and $200 \mu \mathrm{g} / \mathrm{ml}$ for $\mathrm{MK}$ and $50 \mu \mathrm{g} / \mathrm{ml}$ for silymarin and $40 \mu \mathrm{M}$ for PCM). In in-vivo study, animals were grouped in six, namely, vehicle, PCM control, silymarin $(50 \mathrm{mg} / \mathrm{kg}$, standard), MK (100 and $300 \mathrm{mg} / \mathrm{kg})$ groups. Animals were dosed for 8 days while they were challenged on day 6 (except vehicle group) with PCM $(2.75$ $\mathrm{g} / \mathrm{kg}$ p.o). On day 8 , blood and livers were collected under anaesthesia and analyzed. Results: In-vitro results showed hepatoprotection by MK and silymarin by inhibition of PCM-induced cell death apoptotic cells percentage. In in-vivo study, MK and silymarin reversed the altered liver function and elevated oxidative stress markers (catalase, SOD, GSH, total thiols and lipid peroxidation) compared to paracetamol alone group. Both MK and silymarin decreased the percentage of DNA fragmentation and histopathological changes in liver tissue compared to the PCM group. Conclusion: The in-vitro and in-vivo studies showed the hepatoprotective effect of MK by the prevention of PCM-induced induction of oxidative stress by its antioxidant potential thereby preventing PCM-induced DNA damage.
\end{abstract}

Key words: Megakutki, Paracetamol, Hepatoprotection, Cell viability, Hep G2.

\section{INTRODUCTION}

Liver is an important organ to regulate key biochemical events that helps in nutrient supply, growth, protection against xenobiotics, energy supply and to fight against pathogens. Due to its multifaceted functions, liver is one of the main organs exposed to various toxicity hazards.
Hepatocytes, the functional units of the liver, combat these hazards with the tremendous regenerating capacity. ${ }^{1}$ Despite this regenerating capacity, liver damage is a major disease affecting people worldwide. More than 900 drugs, toxins and herbs have been found to cause hepatotoxicity and
Submission Date: 23-04-2020; Revision Date: 14-07-2020; Accepted Date: 15-09-2020

DOI: 10.5530/ijper.54.4.203 Correspondence: Dr. Nitesh Kumar Assistant Professor, Selection Grade, Department of Pharmacology, Manipal College of Pharmaceutical Sciences, Manipal Academy of Higher Education, Manipal, Karnataka-576104, INDIA.

Phone no: +91-08202922482

Email id: niteshkumar43@ gmail.com

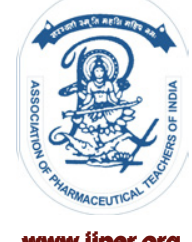

wwwilper.org 
also making it one of the main reasons for the drug withdrawal. ${ }^{2}$ There is a lack of drugs in the modern system of medicine which can treat the hepatotoxicity condition. The treatment approach mainly depends on the symptoms by the use of antibiotics, anti-viral drugs, interferon, immunosuppressant's and corticosteroids. However, these drugs mainly treat the cause and do not provide any support to the liver for regeneration. There is a preference for an alternative system or traditional systems of medicines to treat liver ailments, due to the unavailability of regenerators in the modern system of medicine. That is why drugs like silymarin have gained popularity as a regenerator or protector. ${ }^{3}$

Considering the importance of herbal medicine in the treatment of liver ailment and their popularity in developing and underdeveloped countries, this study was planned to assess a combination of known hepatoprotective extracts against paracetamol (PCM) induced hepatotoxicity. This particular model was chosen since PCM is one of the well-known and common inducers of fulminant hepatic failure. ${ }^{4}$ Toxicity to the liver cells is brought about by a metabolite of PCM namely, $\mathrm{N}$-acetyl-p-benzoquinone imine (NAPQI), which initially binds to copious mitochondrial proteins leading to series of events like mitochondrial pore opening (membrane permeability transition), swelling of the matrix and lysis of outer membrane. This lysis and increased permeabilization results in the release of endonucleases which gets translocated to the nucleus and causes fragmentation of nuclear DNA. ${ }^{5,6}$

Megakutki, a polyherbal formulation, consisting of 11 standardized extracts namely Picrorrbiza kurroa ${ }^{7}$ and Andrographis paniculata, ${ }^{8}$ Tinospora cordifolia Phyllanthus niruri, ${ }^{9}$ Boerbavia diffusa, ${ }^{10}$ Phyllanthus emblica, ${ }^{11}$ Terminalia billerica, ${ }^{12}$ Terminalia chebula, ${ }^{13}$ Eclipta alba, ${ }^{14}$ Zingiber officinale $^{15}$ and Piper longum ${ }^{16}$ which are already known for their hepatoprotection individually. These extracts are individually rich in polyphenols and tannins, which are powerful antioxidants. They can react with active oxygen radicals, such as superoxide anion radicals, hydroxyl radicals and lipid peroxide radicals and inhibit lipid oxidation which can prevent cell damage. Thus, the present study was aimed to determine the in vivo hepatoprotective effect of the formulation against paracetamol in rats and to explore the in vitro preventing effect of this formulation against paracetamol-induced apoptosis in Hep G2 cell lines. Further, the study was also designed to address the safety of the formulation in acute toxicity study.

\section{MATERIALS AND METHODS}

\section{Chemicals, formulations and Drugs}

MK was supplied by Umalaxmi Organics Private Limited, Jodhpur, India. Megakutki ${ }^{\circ}(\mathrm{MK})$ was a polyherbal preparation where each capsule consisted 11 standardized extracts namely Picrorrbiza kurroa - $40 \mathrm{mg}$; Andrographis paniculata - $12.5 \mathrm{mg}$; Phyllanthus niruri -12.5 mg; Boerbavia diffusa - 25 mg; Tinospora cordifolia - 10mg; Phyllanthus emblica - $75 \mathrm{mg}$; Terminalia billerica - $25 \mathrm{mg}$; Terminalia chebula - 25 mg; Eclipta alba - 25 mg; Zingiber officinale - $25 \mathrm{mg}$; Piper longum - 25mg. Cell culture media, growth factors, buffers and reagents were purchased from Himedia, Laboratories Pvt. Ltd, India. Paracetamol (PCM) was provided as a gift sample from Lupin Limited, Pune, India. The diagnostic kits used for biochemical estimation of serum samples were purchased from Aspen Laboratories, India. The other chemicals used in the study were from SD fine chemicals, Mumbai, India.

\section{Cell lines and animals}

The human liver cancer cell line (Hep G2) was purchased from National Center for Cell Sciences, India. The cells were revised and sub-cultured in the tissue culture lab of the Pharmacology Department of Manipal College of Pharmaceutical Sciences, India. The acute toxicity study and hepatoprotective study procedures were approved by the Ethical Committee and approved (IAEC/ KMC/932015). Inbred male and female Wistar rats of 10 to 12 weeks old were used in this study. They were maintained under standard animal house husbandry conditions as mentioned in the Committee for the Purpose of Control and Supervision of Experiments on Animals, India.

\section{Phytochemical analysis of formulation}

The polyherbal formulation was subjected to quantitative analysis for total phenolic content, ${ }^{17}$ total flavonoid content and total tannin content ${ }^{17,18}$ as per the standard procedures.

\section{In-vitro Hepatoprotective Study in Hep G2 Cell line}

\section{Cell viability assay for dose determination of $M K$ and PCM}

A dose-dependent toxicity profile $\left(\mathrm{IC}_{50}\right)$ was performed for MK and paracetamol in Hep G2 cells. Cytoprotection study was evaluated using MTT [3-(4,5-dimethylthiazol-2-yl)-2,5-diphenyl tetrazolium bromide] assay. ${ }^{19}$ After $24 \mathrm{~h}$ of seeding the cells, it was exposed to different concentrations of MK (25 to 400 $\mu \mathrm{g} / \mathrm{ml})$ or paracetamol $(6.25$ to $100 \mathrm{mM})$. The viability of cells was evaluated after $72 \mathrm{~h}$ of exposure of MK and $48 \mathrm{~h}$ after PCM by adding MTT $(20 \mu \mathrm{l}, 5 \mathrm{mg} / \mathrm{mL})$ followed by $100 \mu \mathrm{l}$ DMSO for solubilization. The color was visualized at $540 \mathrm{~nm}$ using ELx800 plate reader of BioTek Instruments Inc., USA. ${ }^{19}$

\section{In-vitro Hepatoprotective studies using MTT assay}

The protective effect of MK was evaluated against PCM (40 mM) in Hep G2 cell line using MT'T assay. Two concentrations of $\mathrm{MK}$ were selected to test the protective effect of MK against PCM-induced hepatotoxicity which 
were 100 and $200 \mu \mathrm{g} / \mathrm{ml}$. Following $24 \mathrm{~h}$ of incubation with MK, toxicant PCM $(40 \mathrm{mM})$ was added and incubated for $48 \mathrm{~h}$. Cytoprotection was assessed using MT'T assay. ${ }^{19}$

\section{Cell cycle analysis of Hep G2 cells}

Exponentially growing cells were harvested from tissue culture flask and grown in sterile 6 well plates for 24 hrs. After $24 \mathrm{hr}$, cells were treated with two doses of Megakutki and the plates were further incubated for $24 \mathrm{hr}$. After $24 \mathrm{hr}$, cells were treated with PCM and were further incubated for $24 \mathrm{hrs}$. After $72 \mathrm{hr}$, the media was aspirated and the plates were washed twice with phosphate buffer saline (PBS). Next, the cells were trypsinized, suspended in PBS and were centrifuged. The obtained pellet was suspended in ice-cold ethanol (70\%) and incubated for 1 $\mathrm{hr}$ in $4^{\circ} \mathrm{C}$. After incubation, cells were again centrifuged and the pellet resuspended in PBS. Cells were centrifuged again and the pellet resuspended in PBS containing Propidium iodide for $20 \mathrm{~min}$ in dark. After $20 \mathrm{~min}$ cells were analyzed using a flow cytometer.

\section{Apoptosis/necrosis estimation in Hep G2 cells by Acridine orange/Ethidium bromide (AO/EB) staining}

Hep G2 cells were incubated with PCM $(40 \mathrm{mM})$, either alone or in combination with MK (at 100 and $200 \mu \mathrm{g} /$ $\mathrm{ml}, 24 \mathrm{~h}$ incubation prior to PCM exposure) in 6 well plates. After $24 \mathrm{~h}$ of incubation, cells were washed by PBS and fixed at room temperature with cold ethanol ( $1 \mathrm{ml}$ for $10 \mathrm{~min})$. After that $1 \mathrm{ml} \mathrm{AO} / \mathrm{EB}$ reagent stain per well was added and incubated for $10 \mathrm{~min}$ at $37^{\circ} \mathrm{C}$. The morphological examination of cells (apoptotic vs necrotic cells) were performed using Inverted microscope with fluorescence filters. ${ }^{20}$

\section{In-vivo hepatoprotective activity against PCM-induced hepatotoxicity in rats}

Thirty-six female Wistar rats were divided into 5 groups consisting of 6 animals in each group. Group 1 was treated orally with $0.25 \%$ carboxymethylcellulose solution (CMC) at a volume of $1 \mathrm{ml} / 100 \mathrm{~g}$ of the rat. Group 2 was treated with CMC like Group 1 rats. Group 3 rats received silymarin (50 mg/ $\mathrm{kg}$, p.o), while Group 4 and 5 received MK at 100 and $300 \mathrm{mg} / \mathrm{kg}$ p.o. respectively for 8 days. On the $6^{\text {th }}$ day, all the rats except group 1 were administered with a single-dose of PCM $(2.75 \mathrm{~g} / \mathrm{kg}$, p.o), one hour after the administration of vehicle/silymarin/MK. ${ }^{20}$ On the $8^{\text {th }}$ day, the animals were anesthetized, blood samples were removed by cardiac puncture. The blood samples were processed for hematological estimations and to obtain serum. The serum samples were used to estimate aspartate transaminase (AST), alanine transaminase (ALT), total bilirubin and total protein. A portion of the liver was used for histological examination and the remaining part was homogenized in 10\% potassium chloride solution.
The homogenate was used to estimate total protein, GSH, Catalase, superoxide dismutase, thiobarbituric acid and total thiols as per our routine laboratory methods. ${ }^{21}$ Subsequently, part of the liver homogenate was subjected to DNA isolation by chloroform: isoamyl alcohol extraction method. The DNA was precipitated by the addition of ethanol. Then the DNA was subjected to gel electrophoresis to analyze the DNA fragmentation pattern with PCM treatment and MK treatments. ${ }^{22}$

\section{Acute oral toxicity in rats}

Acute oral toxicity of MK was performed according to OECD guidelines 425. Briefly, the nulliparous and non-pregnant females of 10 to 12 weeks old were used in this study. Initially, a single dose of $2000 \mathrm{mg} / \mathrm{kg}$ was given to a rat and was closely observed for signs of toxicity, survival or death for 14 days.

\section{Statistical Analysis}

Data are expressed as mean \pm SEM. Statistical differences in means were determined using one-way analysis of variance followed by Tukey's post hoc test using a trial version of Prism software (Version 5.03, GraphPad Software Inc., La Jolla, CA, USA). A probability value of less than $p<0.05$ was considered significant.

\section{RESULTS}

\section{Phytochemical Estimations}

MK had a high amount of phenolic and tannin content. In $200 \mu \mathrm{g}$ of formulation, the total phenolic content was $110.35 \pm 1.83 \mu \mathrm{g}$ as per gallic acid equivalent while the tannin content was $57.73 \pm 0.47 \mu \mathrm{g}$ as per tannic acid equivalent.

\section{Effect of MK, silymarin and PCM on Hep G2 cell line}

$\mathrm{MK}$, silymarin and PCM produced a dose-dependent reduction in cell viability of Hep G2 cell line. The $\mathrm{IC}_{50}$ values of silymarin, $\mathrm{MK}$ and PCM were found to be $106.4 \mu \mathrm{g} / \mathrm{ml}, 414.2 \mu \mathrm{g} / \mathrm{ml}$ and $35.98 \mu \mathrm{M}$ (Figure 1). More than $70 \%$ of the cells are confluent at 100 and $200 \mu \mathrm{g} /$ $\mathrm{ml}$ doses of MK while similar observations were seen at $50 \mu \mathrm{g} / \mathrm{ml}$ of silymarin. Based on these observations, the hepatoprotective doses for $\mathrm{MK}$ were selected as 100 and $200 \mu \mathrm{g} / \mathrm{ml}$ whereas, for silymarin $50 \mu \mathrm{g} / \mathrm{ml}$. Almost $50 \%$ of the cells died with $40 \mathrm{mM}$ concentration of PCM which was selected as a toxic concentration of PCM.

\section{Protective effect of MK against PCM and inhibition of apoptosomes in Hep G2 cell lines}

PCM at $40 \mathrm{mM}$ concentration caused $49.37 \pm 1.56$ percent cell death in Hep G2 cell line. A dose-dependent protection against PCM toxicity was observed for silymarin and MK. Pretreated with MK (100 and 200 
$\mu \mathrm{g} / \mathrm{ml})$ and silymarin $(50 \mu \mathrm{g} / \mathrm{ml})$ prevented the cell death against PCM $(40 \mathrm{mM})$. Maximum protection was seen at $50 \mu \mathrm{g} / \mathrm{ml}$ of MK [Table 1].

Further, AO/EB staining revealed that PCM significantly increased the percentage of apoptotic cells to about $91.32 \pm 0.688$. Treatment with MK at both dose levels and silymarin significantly reduced the percentage of apoptotic cells against the PCM challenge [Figure 2].

\section{Effect of MK on acute oral toxicity}

Single-dose treatment with MK at $2000 \mathrm{mg} / \mathrm{kg}$ did not cause any behavioral change or death in any of the rats.

\section{Liver function tests}

PCM significantly $(p<0.05)$ elevated the AST value with respect to vehicle control group. Treatment with silymarin (standard) and test drug Megakutki at both doses exhibited a significant $(p<0.05)$ reduction in AST levels with respect to the PCM alone treated group. However, no dose-dependent relationship was observed in Megakutki's treatment.

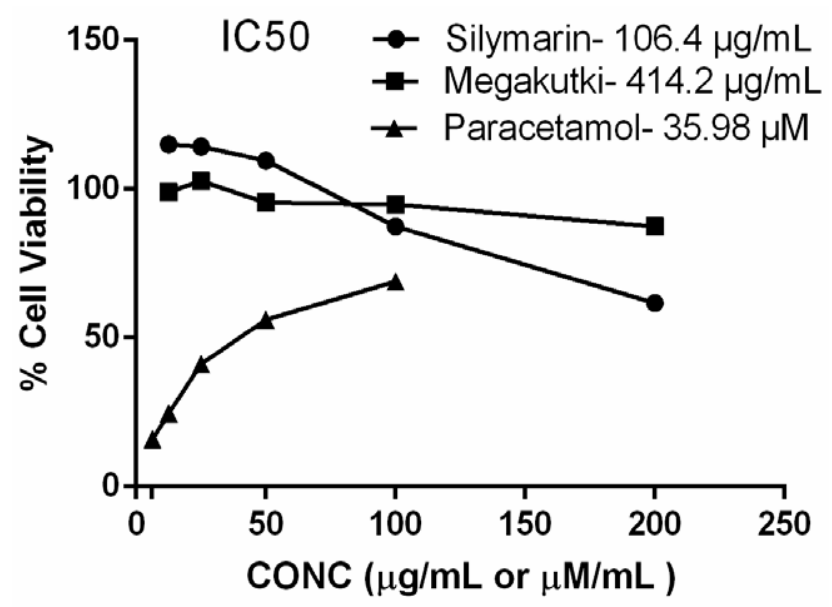

Figure 1: $I_{50}$ values of all drugs with concentration and \% cell viability.
A similar effect was seen on the ALT parameters, PCM treatment in the disease control group showed a significant $(p<0.05)$ elevation in ALT levels with respect to the vehicle control group. Silymarin and the test
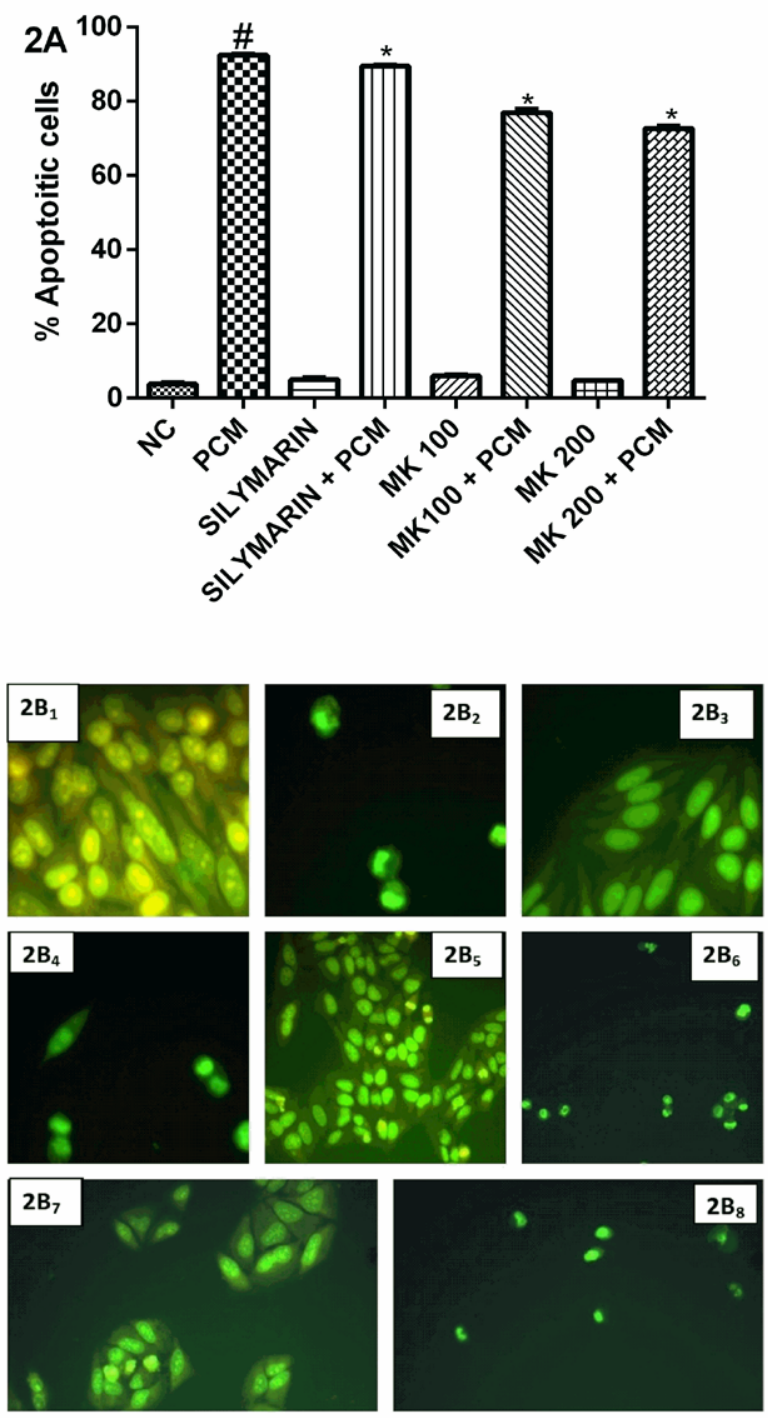

Figure 2: Effect drugs on paracetamol mediated apoptosis on HepG2.

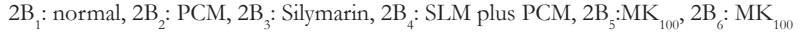
plus PCM, 2B: $\mathrm{MK}_{200} 2 \mathrm{~B}_{8}: \mathrm{MK}_{200}$ plus PCM

\begin{tabular}{|c|c|c|c|c|c|}
\hline Drug name & Conc. $(\mu \mathrm{g} / \mathrm{ml})$ & $\begin{array}{c}\% \text { Cell Viability in } \\
\text { presence of Paracetamol } \\
(40 \mathrm{mM})\end{array}$ & Drug name & Conc. $(\mu \mathrm{g} / \mathrm{ml})$ & $\begin{array}{c}\% \text { Cell Viability in presence } \\
\text { of Paracetamol }(40 \mathrm{mM})\end{array}$ \\
\hline \multirow{5}{*}{ Silymarin (Std) } & 15.18 & $76.6 \pm 6.51$ & \multirow{5}{*}{ Megakutki } & 25 & $66.95 \pm 2.53$ \\
\hline & 31.25 & $64.3 \pm 1.2$ & & 50 & $70.18 \pm 1.31$ \\
\hline & 62.5 & $43.2 \pm 2.42$ & & 100 & $65.79 \pm 1.96$ \\
\hline & 125 & $59.2 \pm 1.04$ & & 200 & $54.82 \pm 1.6$ \\
\hline & 250 & $42.9 \pm 2.82$ & & 400 & $47.22 \pm 0.52$ \\
\hline
\end{tabular}

$\%$ Cell Viability is represented in terms of mean \pm SEM of three readings. PCM at $40 \mathrm{mM}$ concentration showed $49.37 \pm 1.56$ percent cell death 
drug Megakutki at both doses resulted in a significant $(p<0.05)$ decrease in ALT levels with respect to the PCM group. However, no dose-dependent relationship was observed in Megakutki's treatment.

ALP also showed a similar trend. ALP levels in the PCM group elevated significantly $(p<0.05)$ with respect to the vehicle control group. Silymarin and the test drug Megakutki at $100 \mathrm{mg} / \mathrm{kg}$ exhibited a significant $(p<0.05)$ decrease in the ALP levels with respect to the PCM group. PCM treatment significantly $(p<0.05)$ raised Total Bilirubin levels with respect to the control group. Silymarin and the test drug Megakutki at both doses showed a significant $(p<0.05)$ decrease in total bilirubin levels with respect to the PCM group. However, no dose-dependent relationship was observed in Megakutki treatment [Table 2].

\section{Anti-oxidant measurements}

The catalase activity of the PCM group significantly $(p<0.05)$ minimized with respect to the vehicle group. The standard (silymarin) treatment and the test drug Megakutki at both doses significantly increased the catalase activity with respect to the PCM group. No significant $(\phi<0.05)$ difference was seen between Megakutki at $100 \mathrm{mg} / \mathrm{kg}$ and $300 \mathrm{mg} / \mathrm{kg}$. A similar trend like catalase levels was seen in the SOD activity, GSH and total thiols levels.

Lipid Peroxidation activity (assessed in terms of MDA level) of the PCM group significantly $(p<0.05)$ increased with respect to the vehicle group. Silymarin and Megakutki at both dose levels exhibited a significant $(p<0.05)$ reversal in the lipid peroxidation levels with respect to the PCM group. No significant $(p<0.05)$ difference was seen between Megakutki at $100 \mathrm{mg} / \mathrm{kg}$ and $300 \mathrm{mg} / \mathrm{kg}$. [Table 3].

\section{DNA fragmentation}

The \% of DNA fragmentation in the PCM treated group was found to be the highest within the 5 groups. PCM showed 69\% of fragmentation towards the lower side which indicates apoptosis. The drugs silymarin and both doses groups of Megakutki were found to decrease the $\%$ fragmentation towards the lower side.
Therefore, it showed protection against PCM induced apoptosis [Figure 3].

\section{Histology of Liver}

The sections of normal control showed the normal structure of hepatocytes with classic lobule structure. The sections of the liver treated with PCM showed immense necrosis and neutrophil infiltration with the deranged central vein. The treatment groups sections
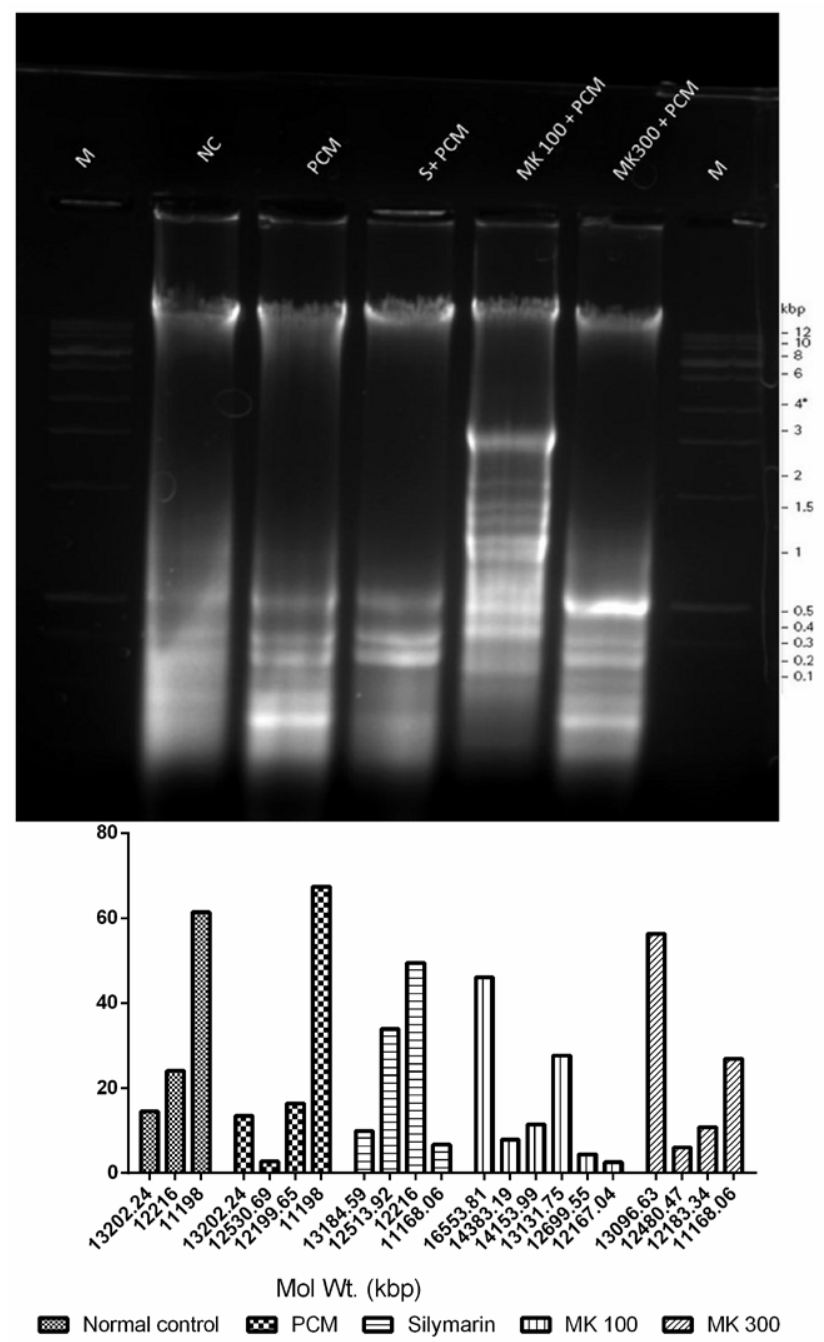

Figure 3: Effect of treatments on DNA fragmentation.

\begin{tabular}{|c|c|c|c|c|c|c|}
\hline Group Name & AST & ALT & ALP & Total Bilirubin & $\begin{array}{c}\text { Direct } \\
\text { Bilirubin }\end{array}$ & Total Protein \\
\hline Normal Control & $160.90 \pm 13.04$ & $44.47 \pm 2.89$ & $89.92 \pm 3.03$ & $0.157 \pm 0.058$ & $0.104 \pm 0.037$ & $7.07 \pm 0.31$ \\
\hline Paracetamol & $280.99 \pm 12.25 \#$ & $252.19 \pm 29.65 \#$ & $139.92 \pm 11.79$ & $0.312 \pm .063 \#$ & $0.104 \pm .039$ & $6.99 \pm 0.21$ \\
\hline Silymarin $50 \mathrm{mg} / \mathbf{k g}$ & $227.59 \pm 18.81^{*}$ & $128.34 \pm 23.67^{*}$ & $81.2 \pm 8.70^{*}$ & $0.142 \pm .039^{*}$ & $0.100 \pm 0.031$ & $6.945 \pm 0.14$ \\
\hline Megakutki -100mg/kg & $211.59 \pm 17.78^{*}$ & $125.08 \pm 18.34^{*}$ & $74.62 \pm 20.2^{*}$ & $0.13 \pm 0.043^{*}$ & $0.104 \pm 0.048$ & $6.586 \pm 0.301$ \\
\hline Megakutki - 300mg/kg & $194.89 \pm 18.64$ * & $130.32 \pm 17.11^{*}$ & $129.92 \pm 10.21$ & $0.172 \pm 0.009^{*}$ & $0.104 \pm 0.034$ & $6.41 \pm 0.35$ \\
\hline
\end{tabular}

All the values are mean $\pm \mathrm{SEM}$, where $\# p<0.05$ compared to the normal group and $* p<0.05$ compared to paracetamol control. 


\begin{tabular}{|c|c|c|c|c|c|}
\hline \multicolumn{7}{|c|}{ Table 3: Effect of Treatment on Antioxidant Levels. } \\
\hline Group Name & Catalase & SOD & GSH & TBARS & Total thiols \\
\hline Normal Control & $8.3 \pm 0.79$ & $438.93 \pm 9.9$ & $6.54 \pm 0.63$ & $110.43 \pm 4.19$ & $18.09 \pm 1.67$ \\
\hline Paracetamol & $5.12 \pm 0.4^{\#}$ & $336.89 \pm 15.27^{\#}$ & $3.36 \pm 0.38^{\#}$ & $133.69 \pm 6.19^{\#}$ & $11.27 \pm 0.47^{\#}$ \\
\hline Silymarin - 50 mg/kg & $8.43 \pm 0.4^{*}$ & $438.01 \pm 16.91^{*}$ & $7.02 \pm 0.8^{*}$ & $105.18 \pm 5.69^{*}$ & $15.65 \pm 0.82^{*}$ \\
\hline Megakutki - $\mathbf{1 0 0} \mathbf{~ m g / k g}$ & $8.39 \pm 0.6^{* *}$ & $436.85 \pm 11.03^{*}$ & $9.3 \pm 0.84^{*}$ & $113.29 \pm 6.23^{*}$ & $15.59 \pm 0.64^{*}$ \\
\hline Megakutki - $\mathbf{3 0 0} \mathbf{~ m g / k g}$ & $9.45 \pm 0.84^{*}$ & $499.86 \pm 33.62^{*}$ & $9.21 \pm 0.89^{*}$ & $106.87 \pm 9.88^{*}$ & $19.24 \pm 2.08^{*}$ \\
\hline
\end{tabular}

All the values are Mean $\pm \mathrm{SEM}$, where $\# p<0.05$ compared to normal control and * $p<0.05$ compared to PCM control.

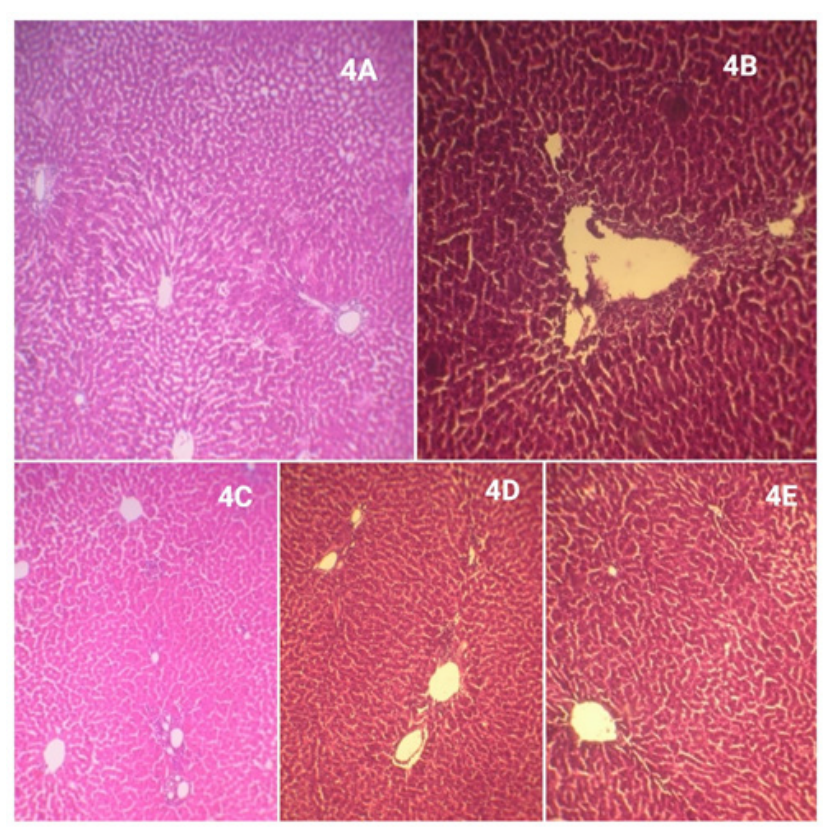

Figure 4: Histopathology of liver.

4A: NORMAL, 4B: PCM, 4C: SLM plus PCM, 4D: $\mathrm{MK}_{100}$ plus PCM, 4E: MK ${ }_{300}$ plus PCM.

of the liver showed some neutrophil infiltration and normal central vein structure [Figure 4].

\section{DISCUSSION}

Phytochemical estimation of Megakutki showed high content of polyphenols and tannin which could contribute to the anti-oxidant property of the polyherbal formulation. The hepatoprotection studies were conducted in-vitro and in-vivo to assess its hepatoprotective potential and the underlying mechanism involved for the same. In-vitro studies were done to evaluate the hepatoprotective effect of the drug on Hep G2 cells.

The in-vitro studies do not exactly reflect the mechanisms of hepatoprotection, because the in vivo systems are associated with multiple growth signaling mechanisms such as insulin, growth hormones, IGF, etc., which are missing in in vitro systems such as in hepatoprotection study in HepG2 cell line. However, the use of in-vitro studies plays an important role in the evaluation of the hepatoprotective effect of drugs against toxicants without much interference from the above-mentioned growth signals.

MTT is a chemical that easily permeates the cell membrane and gets metabolized by the mitochondrial enzyme (succinate dehydrogenase) to formazan, a violet-colored substance. This principle have been used commonly to evaluate the difference in the percentage of viability cells by the drugs at various concentrations in the presence of various toxicants. ${ }^{23}$ In the present study, MT'T assay was used to evaluate the hepatoprotective action of Megakutki on HepG2 cells. Firstly, the $\mathrm{IC}_{50}$ values of the drugs and PCM were assessed. For hepatoprotection study, the toxicant was used at $\mathrm{IC}_{50}$ value while protectants were used at concentrations below $\mathrm{IC}_{50}$ values. The drug concentration was fixed below the $\mathrm{IC}_{50}$ value $(400 \mu \mathrm{g} / \mathrm{mL})$ and that of PCM at $40 \mathrm{mM}$. Treatment with MK prevented PCM-induced toxicity in Hep G2. Based on in vitro protection study, 100 and $200 \mu \mathrm{g} / \mathrm{mL}$ submaximal protection dose) were selected for further mechanistic studies.

Acridine orange/ethidium bromide (AO/EB) staining was done on cells to find out the apoptotic index. In this study, the nuclear content of the apoptotic cells showed bright green fragmented color while it reflected red color in case of necrotized cells. Earlier studies demonstrated the apoptotic potential of PCM upon treatment in liver cells. ${ }^{24}$ Considering this, the cells were pre-treated with $\mathrm{MK}$ and challenged with PCM to assess the protection from the apoptotic inducing nature of PCM. The apoptotic bodies were seen in all the treatment groups, but MK treatment reduced the apoptotic index and thereby increased the cell viability. This showed that Megakutki protected the cells from PCM's toxic insult. Similar changes were observed for standard silymarin.

Acute toxicity study showed that the formulation was safe at a single tested dose of $2000 \mathrm{mg} / \mathrm{kg}$ orally. Based on this and previous experience, two dose levels, 100 and $300 \mathrm{mg} / \mathrm{kg}$ were selected for hepatoprotection study in 
Wistar rats against PCM. High levels of tannin and total phenol of MK can be the reason for this antioxidant potential.

PCM is metabolized by cytochrome P450 enzymes to toxic metabolite NAPQI (N-acetyl- p-benzoquinone imine) that causes oxidative stress and glutathione (GSH) depletion which subsequently leads to lipid peroxidation and cellular damage. ${ }^{25}$ The major factor that is responsible for the toxicity is oxidative stress to the liver cells. The oxidative stress is a result of an inability of the natural antioxidant system of the body to cope up with the rise in the reactive oxygen species formation (ROS). When the antioxidant defence mechanism fails to prevent damage to the cells, the ROS damages macromolecules such as DNA, RNA, lipid, proteins and carbohydrates. In the present in-vivo model of PCM-induced toxicity, an increase in the liver enzyme levels as observed which confirmed hepatotoxicity.

At both dose levels of MK, the AST, ALT and ALP levels were significantly $(\phi<0.05)$ reduced as compared to PCM without dose dependency. This revealed the significant hepatoprotective effect of $\mathrm{MK}$ in in-vivo study in Wistar rats. The reduction of the increased total bilirubin by Megakutki affirm that the drug exhibited hepatoprotective activity against PCM-induced toxicity. PCM decreased the endogenous antioxidant levels significantly with respect to the normal group. MK at $100 \mathrm{mg} / \mathrm{kg}$ and $300 \mathrm{mg} / \mathrm{kg}$ displayed significant $(p<0.05)$ elevation of SOD, catalase and GSH levels compared to the disease control group while it also decreased the MDA level. However, MK did not show any dose-dependent antioxidant effect. This increase in antioxidant level and decrease in MDA level (a marker of oxidative stress) represented the hepatoprotective activity of MK against PCM intoxication through antioxidant mechanisms.

PCM can activate caspase 3 and result in apoptosis, which leads to the fragmentation of DNA. ${ }^{26}$ The DNA ladder assay showed DNA fragmentation, which confirms apoptosis by PCM. The drug treatment decreased the percentage of apoptosis and normalized the damage pattern.

\section{CONCLUSION}

MK showed a protective effect against PCM-induced hepatotoxicity with no evidence of toxicity. So, further clinical trials may be designed to assess the effect of $\mathrm{MK}$ in various liver disorders.

\section{ACKNOWLEDGEMENT}

We thank our institution Manipal College of Pharmaceutical Sciences, Manipal Academy of Higher Education, Manipal, for providing infrastructural support.

\section{CONFLICT OF INTEREST}

We declare no conflict of interest. The Megakutki ${ }^{\circledR}$ was prepared by the authors from Umalaxmi Organics Private Limited, Jodhpur, India for commercial purpose.

\section{ABBREVIATIONS}

MK: Megakutki; PCM: Paracetamol; SOD: superoxide dismutase; GSH: reduced glutathione; MDA: Malondialdehyde; AST: Aspartate transaminase; ALT: Alanine transaminase; ALP: Alkaline phosphatase; ROS: Reactive oxygen species formation; AO/ EB: Acridine orange/Ethidium bromide; CMC: Carboxymethylcellulose solution.

\section{REFERENCES}

1. Michalopoulos GK. Liver regeneration. Journal of Cellular Physiology. 2007;213(2):286-300.

2. Pandit A, Sachdeva T, Bafna P. Drug-induced hepatotoxicity: A review. J Appl Pharm Sci. 2012;2(5):233-43.

3. Girish C, Pradhan SC. Indian herbal medicines in the treatment of liver diseases: Problems and promises. Fundam Clin Pharmacol. 2012;26(2):180-9.

4. Yoon E, Babar A, Choudhary M, et al. Acetaminophen-induced hepatotoxicity: A comprehensive update. Journal of Clinical and Translational Hepatology. 2016;4(2):131.

5. Bajt ML, Cover C, Lemasters JJ, et al. Nuclear translocation of endonuclease $\mathrm{G}$ and apoptosis-inducing factor during acetaminophen-induced liver cell injury. Toxicological Sciences. 2006;94(1):217-25.

6. McGill MR, Sharpe MR, Williams $C D$, et al. The mechanism underlying acetaminophen-induced hepatotoxicity in humans and mice involves mitochondrial damage and nuclear DNA fragmentation. The Journal of Clinical Investigation. 2012;122(4):1574-83.

7. Gupta P, Tripathi A, Agrawal T, et al. Synergistic protective effect of picrorhiza with honey in acetaminophen induced hepatic injury. Indian Journal of Experimental Biology. 2016;54:530-6.

8. Singh DP, Awasthi H, Luqman S, et al. Hepatoprotective Effect of $A$ Polyherbal Extract Containing Andrographis paniculata, Tinospora cordifolia and Solanum nigrum Against Paracetamol Induced Hepatotoxicity. Pharmacognosy Magazine. 2015;11(Suppl 3):S375-9.

9. Bhattacharjee R, Sil PC. The protein fraction of Phyllanthus niruri plays a protective role against acetaminophen induced hepatic disorder via its antioxidant properties. Phytotherapy Research. 2006;20(7):595-601.

10. Olaleye MT, Akinmoladun AC, Ogunboye AA, et al. Antioxidant activity and hepatoprotective property of leaf extracts of Boerhaavia diffusa Linn against acetaminophen-induced liver damage in rats. Food and chemical toxicology: An International Journal Published for the British Industrial Biological Research Association. 2010;48(8-9):2200-5.

11. Thilakchand KR, Mathai RT, Simon P, et al. Hepatoprotective properties of the Indian gooseberry (Emblica officinalis Gaertn): A review. Food and Function. 2013;4(10):1431-41. 
12. Sobeh M, Mahmoud MF, Hasan RA, et al. Chemical composition, antioxidant and hepatoprotective activities of methanol extracts from leaves of Terminalia bellirica and Terminalia sericea (Combretaceae). Peer J. 2019;7:e6322.

13. Gopi KS, Reddy AG, Jyothi K, et al. Acetaminophen-induced Hepato- and Nephrotoxicity and Amelioration by Silymarin and Terminalia chebula in Rats. Toxicol Int. 2010;17(2): 64-6.

14. Tabassum N, Agrawal SS. Hepatoprotective activity of Eclipta alba Hassk. against paracetamol induced hepatocellular damage in mice. JK Practitioner. 2004;11(4):278-80.

15. Yemitan OK, Izegbu MC. Protective effects of Zingiber officinale (Zingiberaceae) against carbon tetrachloride and acetaminophen-induced hepatotoxicity in rats. Phytotherapy Research: PTR. 2006;20(11):997-1002.

16. Jalalpure $\mathrm{S}$, Patil $\mathrm{M}$, Prakash $\mathrm{N}$, et al. Hepatoprotective activity of the fruits of Piper longum linn. Indian Journal of Pharmaceutical Sciences. 2003;65(4):363.

17. Blainski A, Lopes GC, DeMello JC. Application and analysis of the folin ciocalteu method for the determination of the total phenolic content from Limonium brasiliense L. Molecules. 2013;18(6):6852-65.

18. Kumar N, Biswas S, Mathew AE, et al. Pro-apoptotic and cytotoxic effects of enriched fraction of Elytranthe parasitica (L.) Danser against HepG2 Hepatocellular carcinoma. BMC Complementary and Alternative Medicine. 2016;16(1):420
19. Kumar N, Rai A, Reddy ND, et al. Silymarin liposomes improves oral bioavailability of silybin besides targeting hepatocytes and immune cells. Pharmacological Reports: PR. 2014;66(5):788-98.

20. Tiwari A, Kutty NG, Kumar N, et al. Synthesis and evaluation of selected 1, 3, 4-oxadiazole derivatives for in vitro cytotoxicity and in vivo anti-tumor activity. Cytotechnology. 2016;68(6):2553-65.

21. Kumar N, Rai A, Reddy ND, et al. Improved in vitro and in vivo hepatoprotective effects of liposomal silymarin in alcohol-induced hepatotoxicity in Wistar rats. Pharmacological Reports. 2019;71(4):703-12.

22. Kumar N, Raj VP, Jayshree B, et al. Elucidation of Structure-activity Relationship of 2-Quinolone Derivatives and Exploration of Their Antitumor Potential Through Bax-induced Apoptotic Pathway. Chem Biol Drug Des. 2012;80(2):291-9.

23. Lewerenz V, Hanelt S, Nastevska $C$, et al. Antioxidants protect primary rat hepatocyte cultures against acetaminophen-induced DNA strand breaks but not against acetaminophen-induced cytotoxicity. Toxicology. 2003;191(2-3):179-87.

24. McGregor $\mathrm{AH}$, More LJ, Simpson KJ, et al. Liver death and regeneration in paracetamol toxicity. Human and Experimental Toxicology. 2003;22(4):221-7

25. Hinson JA, Roberts DW, James LP. Mechanisms of acetaminophen-induced liver necrosis. Handbook of Experimental Pharmacology. 2010;369-405.

26. Kon K, Kim JS, Jaeschke $\mathrm{H}$, et al. Mitochondrial permeability transition in acetaminophen-induced necrosis and apoptosis of cultured mouse hepatocytes. Hepatology. 2004;40(5):1170-9.

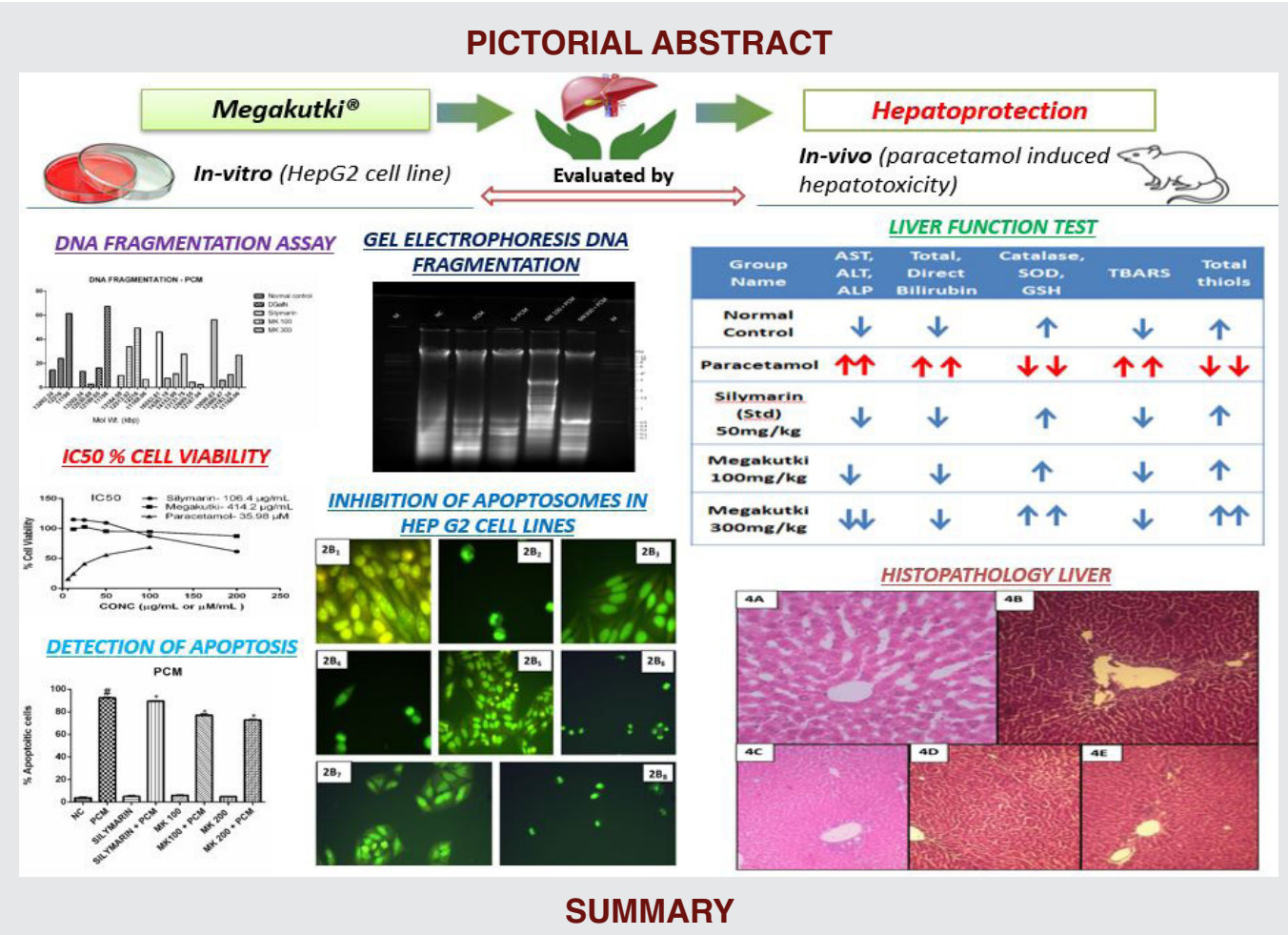

Megakutki ${ }^{\circledR}(\mathrm{MK})$, polyherbal preparation containing known 11 standardized hepatoprotective extracts, was evaluated for its hepatoprotective effect against paracetamol (PCM) in in-vitro and in-vivo. The in-vitro studies on HepG2 cells showed significant protection by MK and silymarin against PCM in cell viability study and mechanistic studies (cell cycle analysis and apoptosis study). The in-vivo study was conducted in Wistar rats, where treatments of the vehicle (carboxymethylcellulose- $0.25 \% \mathrm{w} / \mathrm{v}$ ), silymarin and MK $(100$ and $300 \mathrm{mg} / \mathrm{kg}$ ) were given for 8 days, while PCM $\left(2.75 \mathrm{~g} / \mathrm{kg} \mathrm{p.o.)} \mathrm{challenge} \mathrm{on} \mathrm{the} 6^{\text {th }}\right.$ day except for the vehicle control group. MK and silymarin reversed the altered liver function and oxidative stress markers levels (catalase, SOD, GSH, total thiols and lipid peroxidation) compared to PCM alone group. Both MK and silymarin decreased the percentage of DNA fragmentation and histopathological changes in liver tissue when compared to the PCM group. All these results have proven the hepatoprotection by MK and silymarin by inhibiting cell death and by preventing DNA damage against PCM challenge. 


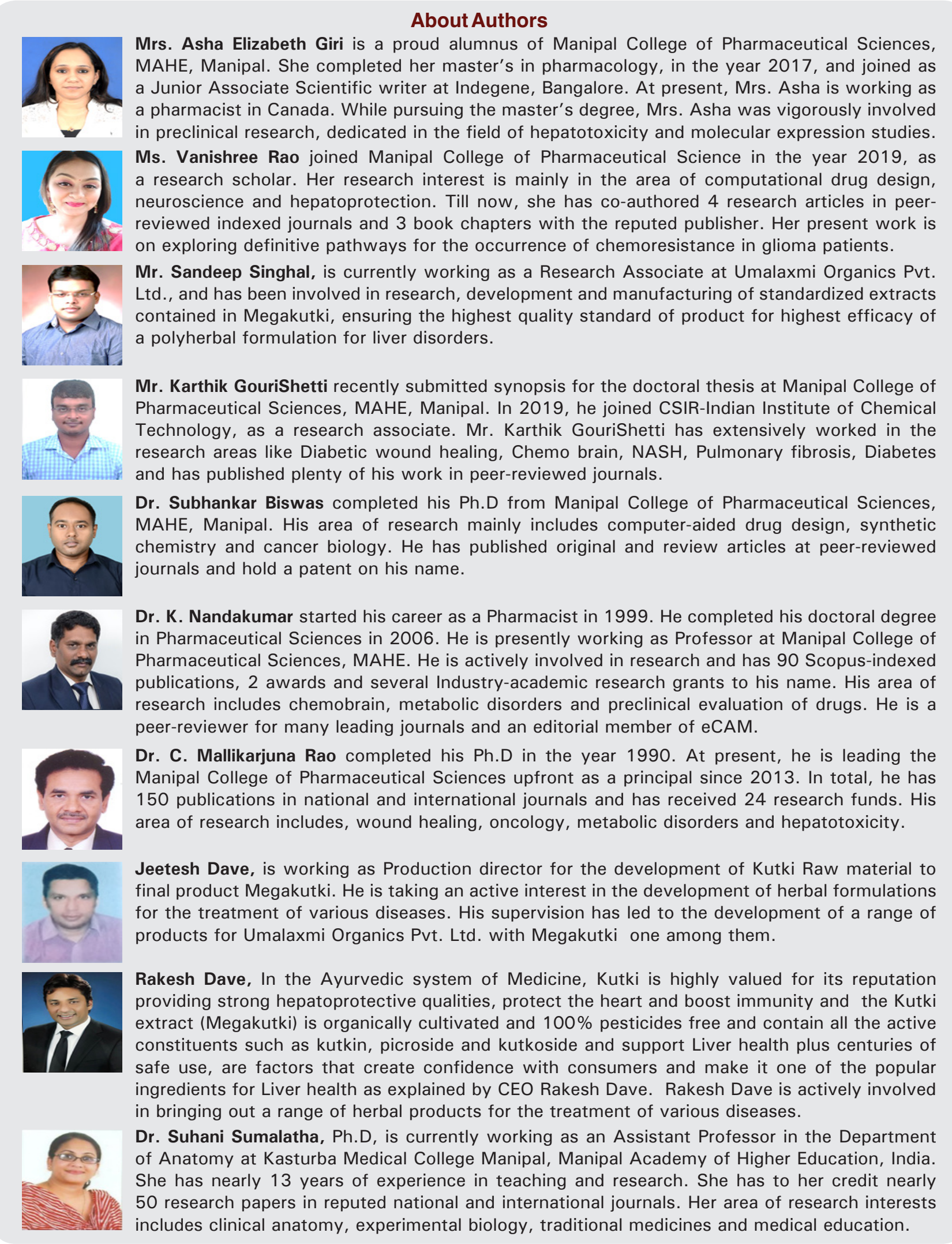

Cite this article: Giri AE, Rao V, Singhal S, GouriShetti K, Biswas S, Nandakumar K, Chamllamudi MR, Dave J, Dave R, Sumalatha S, KumarN. Evaluation of Hepatoprotective Effect of a Polyherbal Megakutki against ParacetamolInduced Hepatotoxicity. Indian J of Pharmaceutical Education and Research. 2020;54(4):1080-8. 